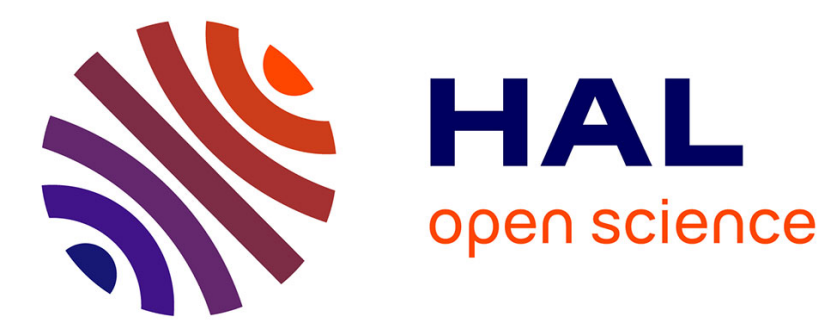

\title{
Heat transfer studies in cold CVD reactors using holographic interferometry
}

\author{
H. Chehouani, S. Benet, S. Brunet, B. Armas
}

\section{To cite this version:}

H. Chehouani, S. Benet, S. Brunet, B. Armas. Heat transfer studies in cold CVD reactors using holographic interferometry. Journal de Physique IV Proceedings, 1993, 03 (C3), pp.C3-83-C3-90. 10.1051/jp4:1993310 . jpa-00251367

\section{HAL Id: jpa-00251367 https://hal.science/jpa-00251367}

Submitted on 1 Jan 1993

HAL is a multi-disciplinary open access archive for the deposit and dissemination of scientific research documents, whether they are published or not. The documents may come from teaching and research institutions in France or abroad, or from public or private research centers.
L'archive ouverte pluridisciplinaire HAL, est destinée au dépôt et à la diffusion de documents scientifiques de niveau recherche, publiés ou non, émanant des établissements d'enseignement et de recherche français ou étrangers, des laboratoires publics ou privés. 


\title{
Heat transfer studies in cold CVD reactors using holographic interferometry
}

\author{
H. CHEHOUANI, S. BENET, S. BRUNET and B. ARMAS \\ LPA, Université de Perpignan, 66860 Perpignan, France \\ ${ }^{*}$ IMP/CNRS, BP. 5, 66120 Odeillo, France
}

\begin{abstract}
The evaluation of holographic interferograms has been reviewed to perform quasi-real time and more accurate measurements of temperature fields within CVD reactors. In this way a powerful image processing device has been annexed to our optical arrangement to perform suitable and fast data acquisition. The evaluation of holographic interferograms is achieved using Fast Fourier Transform algorithm. Temperature fields have been measured within a large cold wall CVD reactor for different cylindrical substrate diameters and also for a conic substrate. We present some useful empirical correlations between Nusselt and Rayleigh numbers. Our aim in this paper is to give some useful experimental data which could be used to improve the validity of mathematical models developed for CVD process.
\end{abstract}

\section{1-INTRODUCTION}

The modern industrial applications of CVD put severe constraints on the qualities of the production of many thin solid films. It is clear that these qualities are strongly related by the interacting influences of hydrodynamics, transport phenomena and chemical reactions occurring in the CVD reactor. To fulfil these constraints, the conventional approaches based on intuition and trial-and error methods must be replaced by a more fundamental understanding of the relevant physico-chemical phenomenon induced by the CVD process. Nowadays, most efforts made in this direction are aimed to develop a general CVD model to optimise both reactor design and process conditions. The validity of such model requires comparisons between theoretical predictions and experimental data. Therefore, it is necessary to develop simultaneously experimental diagnostics of each individual phenomenon in the CVD reactor.

Our contribution, deals with an experimental study of heat transfer in CVD reactors using holographic interferometry. This optical technique has been successfully used first by Bénet to investigate temperature fields in a vertical tubular reactor [1]. Next Gilling used the same method for gas flow diagnostics in an horizontal reactor [2]. In this paper we describe our recent experimental arrangement which has been reviewed to achieve fast and more accurate temperature measurements. Our purpose is to give a set of experimental data characterising heat transfer which could be used to improve computational CVD codes.

\section{2-OPTICAL SETUP}

The experimental arrangement used to investigate heat transfer in a cold-wall CVD reactor is shown in figure 1. An He-Ne laser serves as the light source which is devised by means of a beam-splitter into an 
object and reference beams. An attenuator is inserted on each beam path allowing easy adjustment of the intensity. Both beams are then expanded to parallel waves by a telescope which consists of a filter (hole $20 \mu \mathrm{m}$ in diameter, microscope objective and collimating lens. In order to allow the object wave passing through the reactor, two Pyrex windows (160 $\mathrm{mm}$ in diameter ) are incorporated in the vertical wall; whereas the reference wave falls onto the holographic plate. Temperature variations in the reactor are converted into an interferogram resulting from a real time comparison between every wave emerging from the reactor with the one memorised by the hologram.

\section{3-DATA EVALUATION}

Qualitative investigations like thermal boundary layer thickness and shape could be deduced immediately from an holographic interferogram as it will be outlined in the next section.

Moreover, the interferogram carries high density of information about thermal state of the studied reactor, since each individual irradiance corresponds to an interference phase. If someone is faced with quantitative investigations, which requires the determination of interference phase, interferometric diagnostics turn out to be difficult. Conventional fringe-finding technique uses only irradiance maxima and minima which requires a numerical interpolation after locating the centre of . bright and dark fringes. This method is time-consuming and not accurate. For this reason, it was necessary to use an automated holographic interference fringe evaluation to achieve more accurate and fast temperature measurements. With this in mind, our holographic interferometer is recently equipped with a powerful image processing. This later consists of a charge-coupled-device camera which records the fringe pattern onto a $512 \times 512$ rectangular array of pixels quantized to discrete values ranging from 0 to 255 using a PIP Video Digitizer board. Numerical evaluation using Fast Fourier Transform algorithm (FFT) of temperature profiles across the convective heat flow surrounding hot substrates is done with a 486DX33 Micro-Computer.
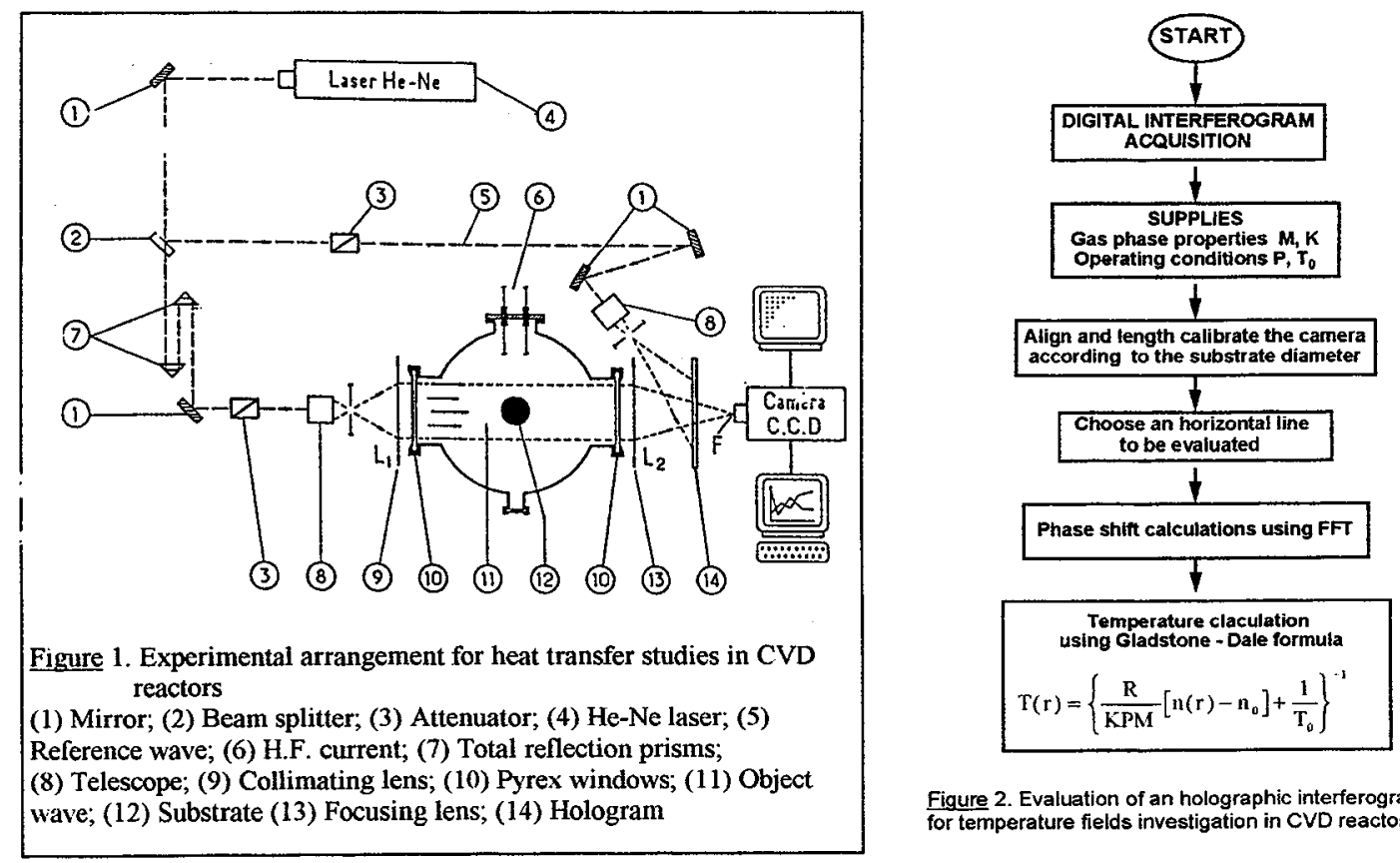

Figure 2. Evaluation of an holographic interferogram for temperature fields investigation in CVD reactors

The evaluation of an interferogram describing temperature fields in the reactor could be done according the flow chart on figure 2 : first, we define gas phase properties (Molar mass M, Gladstone-Dale constant 
$\mathrm{K}$ ) and the operating conditions (reference temperature $T_{0}$ and gas pressure $P$ ). Next two reference lines are drawn on the image of the studied interferogram to align and length calibrate the $C C D$ camera on the TV monitor taking the substrate diameter as reference. Then one can choose any line situated at some distance from the substrate surface (which is chosen here as origin) to be treated. The recorded fringe pattern intensity distribution along this line is subject to a fast Fourier transformation (FFT), leading to a complex frequency dependent distribution [3]. After filtering out background noise and taking the inverse transformation, the interference phase is determined pointwise. The last step in the evaluation of an holographic interferogram consists to invert the interference phase shift distribution to calculate the corresponding refractive index variations in the reactor. The temperature distribution is straightforward deduced using Gladstone formula which relates the temperature to the index of refraction.

The implementation of this method has resulted in the development of a $\mathrm{C}$ computer code "OLOGRAF" which allows to perform nearly real time measurements.

\section{4-DESCRIPTION OF THE REACTOR}

It consists of a vertical stainless-steel cylinder with a diameter and height of $350 \mathrm{~mm}$ [4]. Relatively large, these dimensions lie between those of laboratory studies and those used in industry. The walls are water cooled. Two Pyrex windows with a diameter of $160 \mathrm{~mm}$ are incorporated opposite one another in vertical wall to permit optical analysis of the gas phase temperature in the reactor. The graphite substrate, positioned on the reactor axis is heated by high frequency induction. The water cooled copper coil lies inside the reactor around the substrate keeping an optimal distance from this later to avoid any disturbance on heat transfer in the gas phase. The gas supply is via either of two pipes situated in the upper and lower parts of the reactor.

\section{5-RESULTS}

A set of experimental investigations was carried out in the reactor for several operating conditions in order to give a qualitative and quantitative description of the thermal behaviour of the gas phase in a cold wall CVD reactor.

\section{5-1 Temperature fields}

Temperature fields are determined for three cylindrical substrates (diameters $\Phi_{S}=20,25$ and 30 mm figures 3, 4 and 5). In order to study different and more complicated substrate geometry which could have industrial application, the case of conic substrate has been also considered (figure 6). For each case, we give the infinite fringe interferogram (for qualitative diagnostic of the thermal boundary layer surrounding the sample) and the finite fringe interferogram (for quantitative determination of radial and axial distributions of the temperature below the substrate). The $z$ axis origin is taken at the substrate surface

\section{5-2 Thermal boundary layer}

Informations about thermal boundary layer surrounding the sample could be available using one of the two following optical techniques :

-direct visualisation of the object wave crossing alone the gas phase which behaves as a convergent lens under refractive index gradients. In this way the thermal boundary layer appears as bright line on the background. More details on this optical method applied to the visualisation of thermal boundary layer surrounding the substrate will be the subject of a forthcoming paper.

-observing the fringe patterns on figures 3,4 and 5, this layer is delineated by the area where the fringes are deviated from the vertical finite fringe system. The thermal boundary layer form is approximately elliptic which is schematised in figure by $\delta(r)$. Its thickness is maximal at the centre 


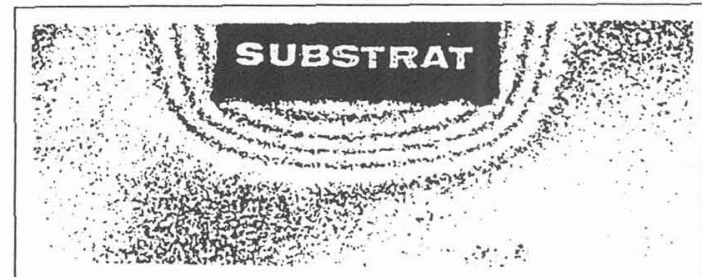

Figure $3 \mathrm{a}$ : infinite fringe interferogram

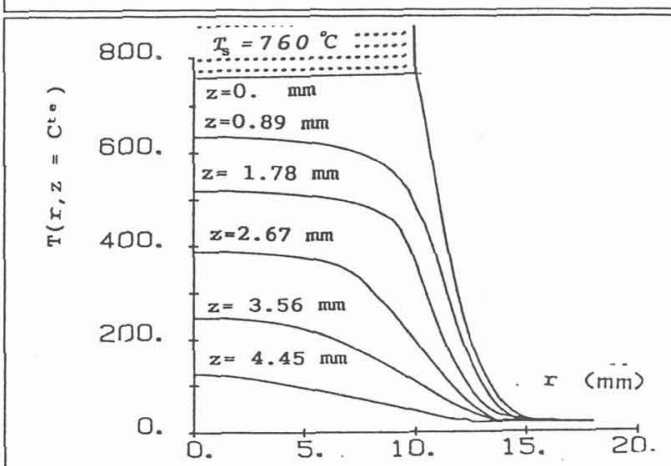

Figure $3 \mathrm{c}$ : radial distribution of temperature

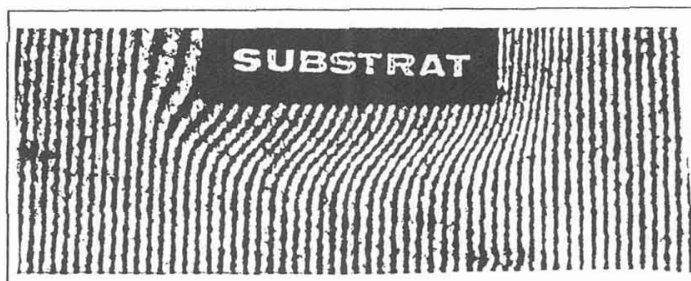

Figure $3 \mathrm{~b}$ : finite fringe interferogram

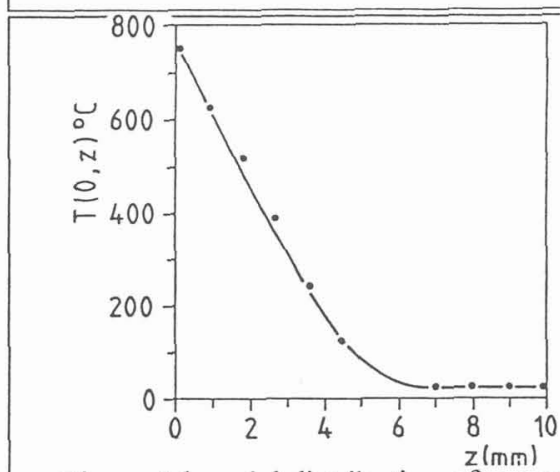

Figure $3 \mathrm{~d}$ : axial distribution of temperature

Figure 3 : temperature field for a substrate diameter $\Phi_{\mathrm{S}}=20 \mathrm{~mm}$ Gas $=$ Argon, $\mathrm{T}_{\mathrm{S}}=760^{\circ} \mathrm{C}, \mathrm{P}=60 \mathrm{kPa}$

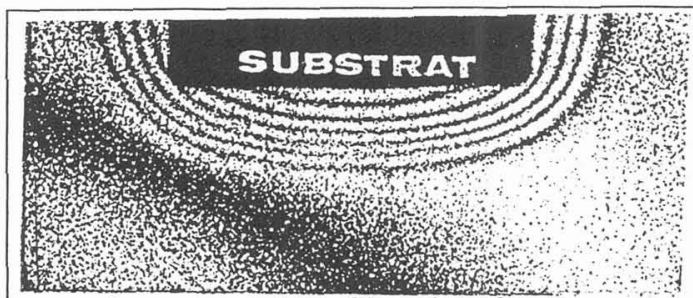

Figure $4 \mathrm{a}$ : infinite fringe interferogram

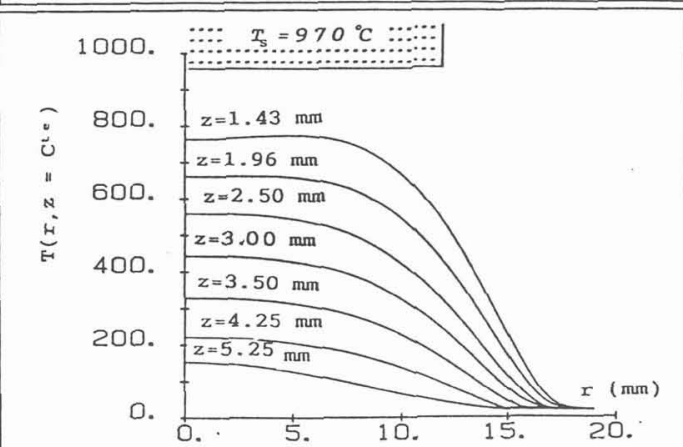

Figure $4 c$ : radial distribution of temperature

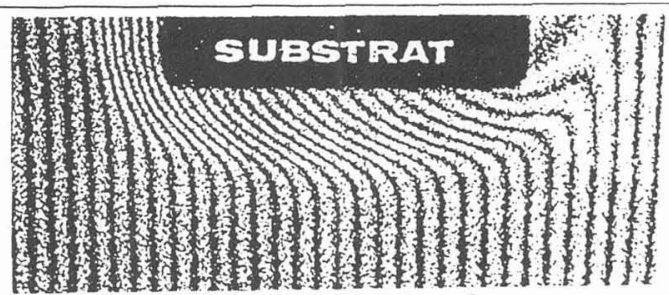

Figure $4 \mathrm{~b}$ : finite fringe interferogram

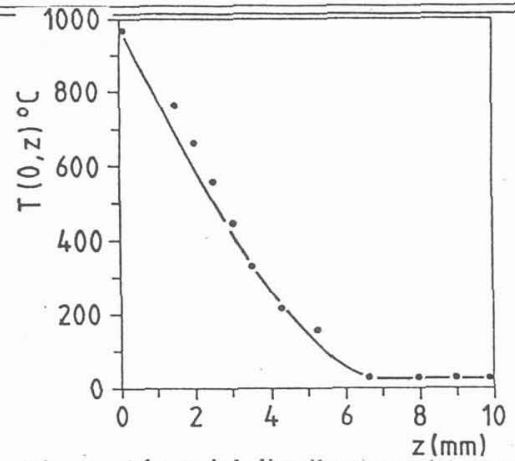

Figure $4 \mathrm{~d}$ : axial distribution of temperature

Figure 4 : temperature field for a substrate diameter $\Phi_{S}=25 \mathrm{~mm}$ Gas $=$ Argon, $\mathrm{T}_{\mathrm{S}}=970^{\circ} \mathrm{C}, \mathrm{P}=66,6 \mathrm{kPa}$ 

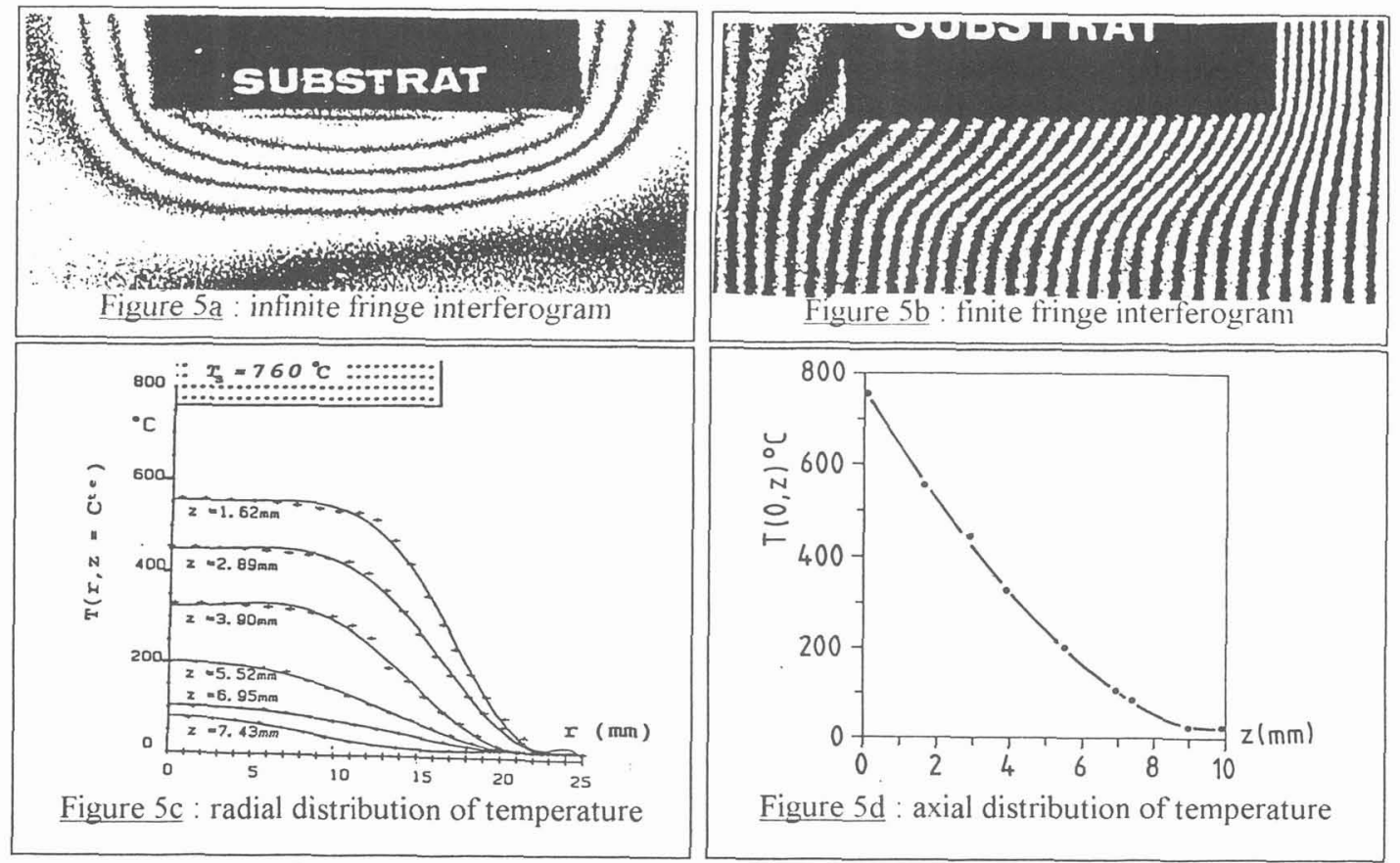

Figure 5 : temperature field for a substrate diameter $\Phi_{\mathrm{S}}=30 \mathrm{~mm}$ Gas $=$ Nitrogen, $\mathrm{T}_{\mathrm{S}}=760^{\circ} \mathrm{C}, \mathrm{P}=45 \mathrm{kPa}$

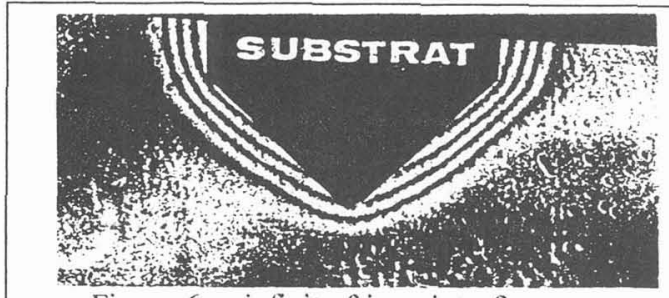

Figure 6a : infinite fringe interferogram

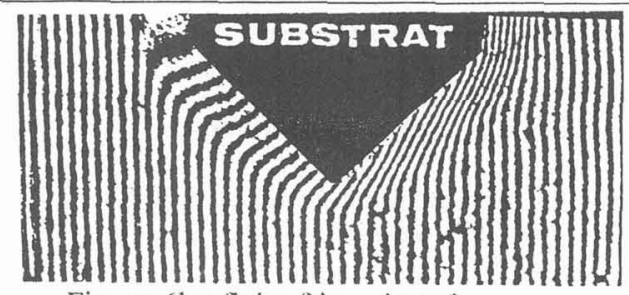

Figure $6 \mathrm{~b}$ : finite fringe interferogram

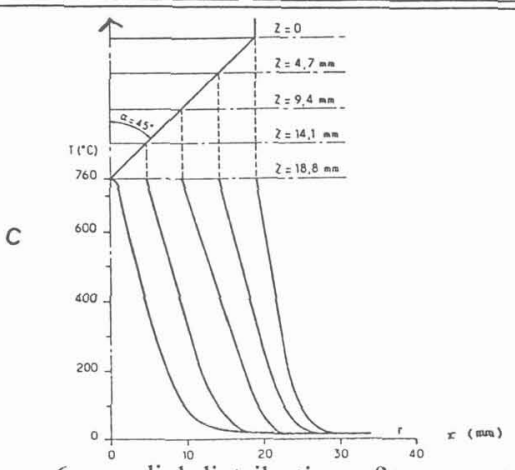

Figure 6c : radial distribution of temperature

Figure 6: temperature field for a conic substrate with a diameter of $\Phi_{S}=38 \mathrm{~mm}$ Gas $=$ Nitrogen, $\mathrm{T}_{\mathrm{S}}=760^{\circ} \mathrm{C}, \mathrm{P}=45 \mathrm{kPa}$ 
$\left(\delta(0)=\delta_{0}\right)$ and decreases towards the substrate edge which indicates high temperature gradient. $\delta_{0}$ is function of several conditions (substrate diameter $\Phi_{s}$, substrate temperature $T_{S}$, gas pressure $P$, inlet gas flow rate $Q$ ). The influence of these parameters on the thermal behaviour of the gas phase has been checked and the results are stimmarised on table 1. It should be emphasised that fringe patterns obtained with a substrate diameter $<40 \mathrm{~mm}$ are stable at all temperatures, and pressure, proving that laminar flows are present in the reactor. However, for a substrate diameter of $40 \mathrm{~mm}$, fringe pattern shows instabilities even at no inlet flow. This indicates that the gas phase in the reactor is the subject of density fluctuations resulting from a turbulent flow in the vicinity of the substrate. We found that pressure is a determinant parameter which affects considerably the stability of temperature fields in the reactor. Pressures greater than $40 \mathrm{kPa}$ cause temperature fluctuations with $150^{\circ} \mathrm{C}$ in magnitude.

Table 1 : influence of operating parameters on heat transfer in the gas phase within the reactor.

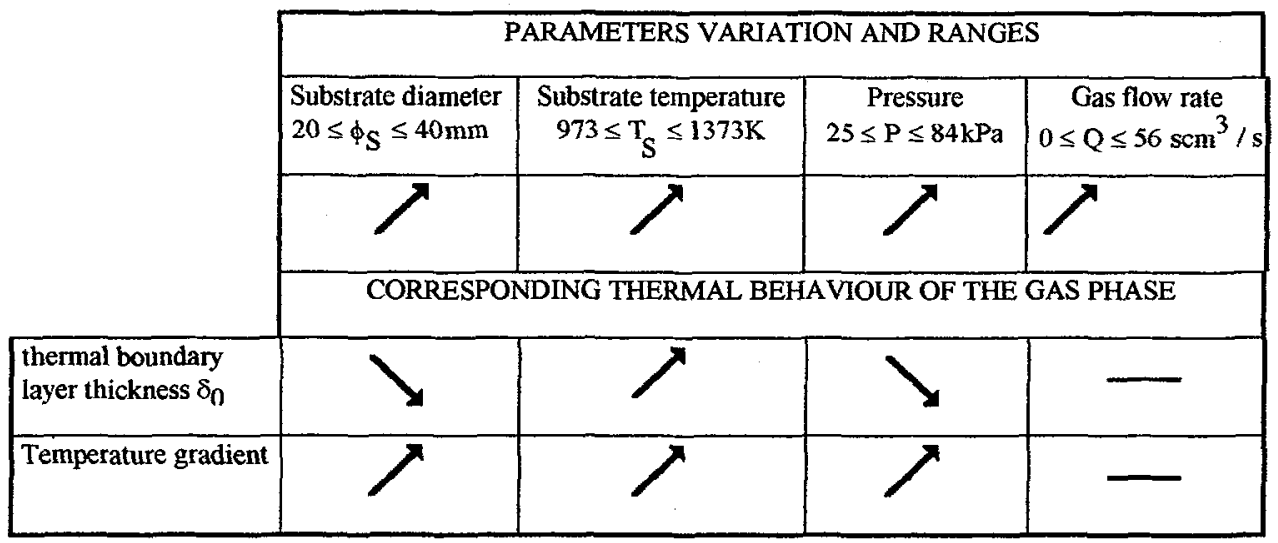

\section{5-3 Heat transfer coefficient}

To characterize heat transfer between the gas phase and the substrate the Nusselt is an obvious choice and could readily be calculated from temperature distributions. However in natural convection dominating flows as encountered in CVD situations, the Nusselt number can be established from the thermal boundary layer thickness which is directly available from an holographic interferogram. In this way, following Singh and al. [5] the local Nusselt number $\mathrm{Nu}(\mathrm{r})$ is given by :

$$
\mathrm{Nu}(\mathrm{r})=\frac{\mathrm{hR}}{\lambda}=\frac{2 \mathrm{R}_{\mathrm{s}}}{\delta(\mathrm{r})}
$$

with $h$ is the heat transfer coefficient, $R_{S}$ is the substrate radius and $\lambda$ is the thermal conductivity

Since the thermal boundary layer thickness at the substrate centre could be measured with a satisfactory accuracy from an holographic interferogram, the following expression may be used to compute the Nusselt number $\mathrm{Nu}_{0}$ at the stagnation point below the substrate :

$$
\mathrm{Nu}_{0}=\frac{2 \mathrm{R}_{\mathrm{s}}}{\delta_{0}}
$$

The Nusselt number is a function of the Rayleigh number which is defined as the product of the Prandtl number and Grashof number : 

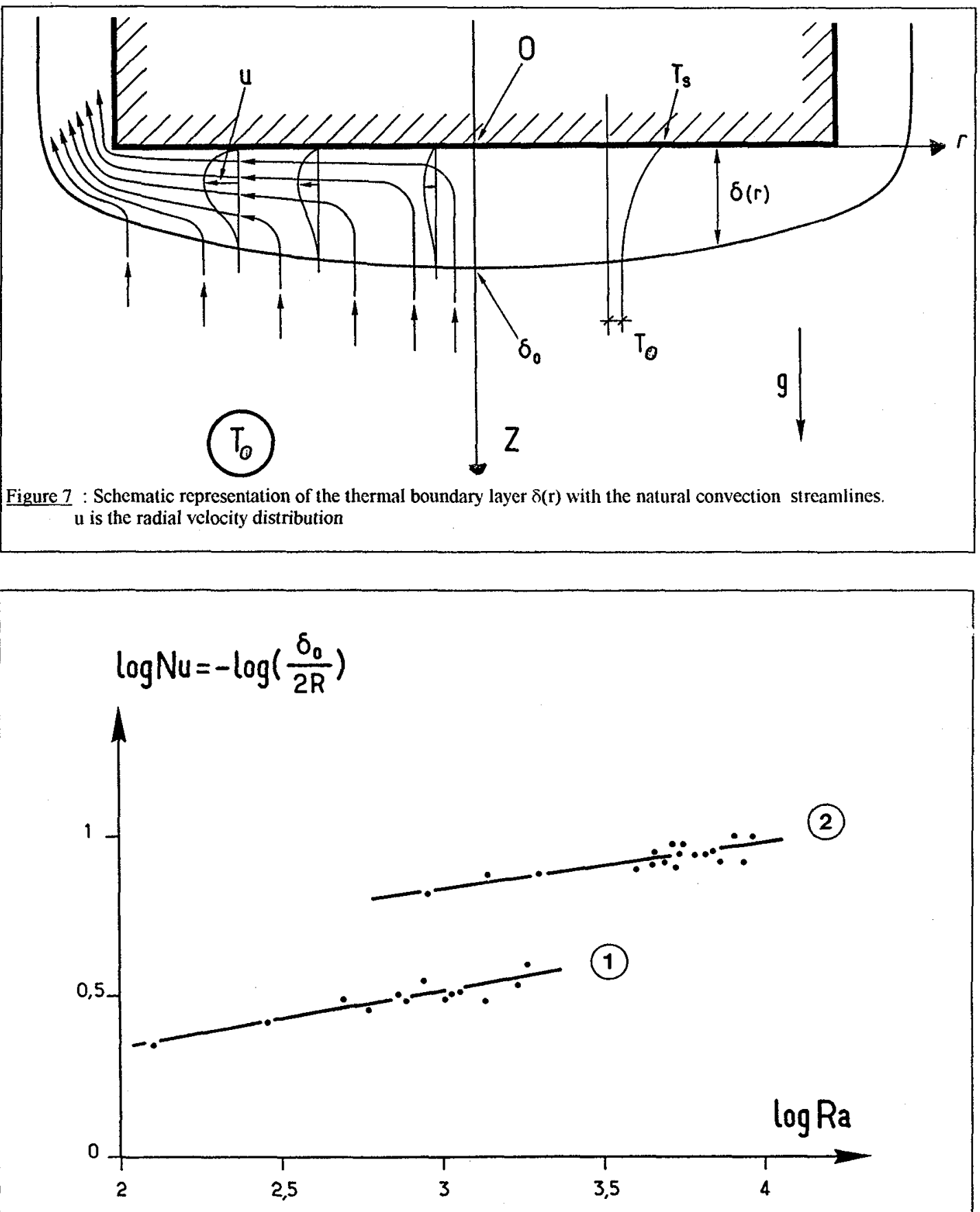

Figure 8 : Local Nusselt numbers at the stagnation point below the substrate

(1) Substrate diameter $\Phi_{S}=20 \mathrm{~mm} \quad$ (2) Substrate diameter $\Phi_{S}=40 \mathrm{~mm}$ 


$$
\operatorname{Ra}=\operatorname{Pr} \cdot G r=\frac{R_{S}^{3} g \beta\left(T_{S}-T_{0}\right)}{v \alpha}
$$

in this expression, $g$ is the gravity acceleration, $\beta$ is the coefficient of thermal expansion, $T_{S}$ is the substrate temperature, $\nu$ is kinematic viscosity and $\alpha$ is the thermal diffusivity. Gas properties used in the expression of the Rayleigh number are computed at the main temperature $\left(T_{S}+T_{0}\right) / 2$. Experimental and theoretical correlations between the Nusselt number and Rayleigh number are usually given in a power law as:

$$
\mathrm{Nu}_{0}=\mathrm{C} \cdot \mathrm{Ra}^{\mathrm{n}} \quad \Leftrightarrow \log \left(\mathrm{Nu}_{0}\right)=\mathrm{C}^{\prime}+\mathrm{n} \cdot \log (\mathrm{Ra})
$$

Figure 8 shows the variation of $\log \left(\mathrm{Nu}_{0}\right)$ as a function of $\log (\mathrm{Ra})$ according to the following laws:

$$
\begin{cases}\mathrm{Nu}_{0}=1,024 \cdot \mathrm{Ra}^{0,1656} & \text { for } \mathrm{R}_{\mathrm{S}}=10 \mathrm{~mm} \\ \mathrm{Nu}_{0}=2,82 \cdot \mathrm{Ra}^{0,1315} & \text { for } \mathrm{R}_{\mathrm{S}}=20 \mathrm{~mm}\end{cases}
$$

\section{6-Conclusion}

The described holographic interferometer coupled to an image processing device provides many advantages that could be used in heat transfer studies within cold CVD reactors. Data acquisition and evaluation using both video signal digitalisation and the FFT algorithm has been found to be more accurate and provide a quasi-real time investigation of temperature fields in the reactor. Qualitative and quantitative experimental data presented in this work could be useful to improve the validity of mathematical models developed for CVD process.

\section{References}

[1] BENET S., BERGE R., BRUNET S., CARLES D., ARMAS B., COMBESCURE C., Proc. Third European Conf. on CVD, Edited by Hintermann'H. P., Neuchâtel, Switzerland, (1980) p 97

[2] GILLING L. J., J. Electochem. Soc., $129 \mathrm{n}^{\circ} 3$ (1982)

[3] KREIS T., J. Opt. S.o.c. Am. A 3, n 6 (1986) pp 447-855

[4] CHEHOUANI H, Doctorate thesis, Université de Perpignan France $\mathrm{N}^{\circ} 101 \mathrm{C}$ (1990)

[5] SINGH S.N., BIRKEBAK R.C., BRAKE R.M., Progr. in Heat and Mass Transfer 2, Pergamon Press. Oxford (1969) pp 87-98 